\title{
IDENTIFIKASI JALUR PEDESTRIAN PANGLIMA BESAR SUDIRMAN NGANJUK SEBAGAI KORIDOR YANG LIVABLE
}

\author{
Stivani Ayuning Suwarlan \\ Universitas Internasional Batam, Program Studi Arsitektur \\ stivani@uib.ac.id
}

\begin{abstract}
Pedestrian ways as a good city public space must meet the principles of livable city, which has mobility that is easy to walk and has aesthetic value. The problem of the pedestrian ways of the Panglima Besar Sudirman Nganjuk is the lack of facilitating pedestrian facilities and the lack of aesthetics along the pedestrian pathway causing low pedestrian mobility. This study uses a qualitative descriptive method that is revealed according to the facts in the field with a walk through analysis technique. The analysis technique is used to parse, audit and evaluate the physical elements in the pedestrian path based on the observations of researchers and community perceptions and to determine people's perceptions of their environment. This research eventually resulted in the direction of the pedestrian path design of the Panglima Besar Sudirman Nganjuk to make the road corridor livable and provide aesthetic value so that pedestrian mobility increases.
\end{abstract}

Key Words: pedestrian ways, livable city, walk through analysis

\begin{abstract}
Abstrak. Jalur pedestrian sebagai ruang publik kota yang baik haruslah memenuhi prinsip-prinsip livable city yakni memiliki mobilitas yang mudah untuk berjalan kaki serta memiliki nilai estetika. Permasalahan jalur pedestrian Panglima Besar Sudirman Nganjuk adalah tidak terfasilitasinya kemudahan bagi pejalan kaki dan kurangnya estetika pada sepanjang jalur pedestrian sehingga menyebabkan mobilitas pejalan kaki yang rendah. Penelitian ini menggunakan metoda deskriptif kualitatif yaitu mengungkapkan sesuai fakta-fakta yang ada di lapangan dengan teknik analisis walk through analysis. Teknik analisis tersebut digunakan untuk mengurai, mengaudit serta mengevaluasi elemen-elemen fisik pada jalur pedestrian berdasarkan hasil pengamatan peneliti dan persepsi masyarakat serta untuk mengetahui persepsi masyarakat terhadap lingkungannya. Penelitian ini pada akhirnya menghasilkan arahan desain jalur pedestrian Panglima Besar Sudirman Nganjuk untuk menjadikan koridor jalan menjadi livable dan memberikan nilai estetika sehingga mobilitas pejalan kaki meningkat.
\end{abstract}

Kata Kunci : jalur pedestrian, livable city, walk through analysis

\section{PENDAHULUAN}

Kota adalah suatu ciptaan peradaban umat manusia dalam perkembangan manusia yang berawal dari kelompok hingga membentuk koloni membutuhkan kawasan hunian yang lebih besar dan kompleks. Kawasan hunian tersebut terus berkembang hingga membentuk sebuah kawasan hunian yang disebut 'kota'. Sebuah kota yang baik haruslah layak dan nyaman untuk ditinggali atau dihuni oleh masyarakatnya (livable city). Untuk itu, sebuah kota haruslah dikembangkan agar menjadi kota yang layak dan nyaman bagi masyarakat dengan memiliki mobilitas yang mudah untuk berjalan kaki, memiliki wilayah/area publik sebagai tempat bersosialisasi masyarakat karena aktivitas dan komunikasi masyarakat sangat penting bagi sebuah kota, memenuhi fungsi ekonomi, sosial dan budaya serta pertimbangan terhadap estetika dan lingkungan fisik harus memiliki prioritas tinggi (Palej, 2000) dan (Lennard, 1997).

Nganjuk merupakan salah satu kota di Jawa Timur yang merupakan kota dalam tahap berkembang. Perkembangan suatu kota sangat dipengaruhi oleh keberadaan masyarakat dikarenakan perkembangan suatu kota bersamaan dengan berkembangnya koridor yang livable.

Jalur pedestrian merupakan salah satu elemen koridor perkotaan yang merupakan fasilitas ruang publik bagi masyarakat. Jalur pedestrian sebagai ruang publik kota yang baik haruslah memenuhi prinsip-prinsip livable city yakni memiliki mobilitas yang mudah untuk berjalan kaki serta memiliki nilai estetika.

Permasalahan jalur pedestrian Panglima Besar Sudirman Nganjuk adalah tidak terfasilitasinya kemudahan bagi pejalan kaki dan kurangnya estetika pada sepanjang jalur pedestrian 
sehingga menyebabkan mobilitas pejalan kaki yang rendah. Untuk itu, diperlukan sebuah jalur pedestrian yang memfasilitasi kemudahan mobilitas masyarakat dan bernilai estetika sebagai menjadikan koridor menjadi livable.

\section{TUJUAN}

Tujuan dari penelitian ini adalah memberikan arahan desain jalur pedestrian Panglima Besar Sudirman Nganjuk untuk menjadikan koridor jalan menjadi livable dan memberikan nilai estetika sehingga mobilitas pejalan kaki meningkat.

\section{METODOLOGI}

Metode penelitian yang diterapkan adalah metode deskriptif kualitatif yaitu mengungkapkan sesuai fakta-fakta yang ada di lapangan dengan teknik walk through analysis untuk mengurai, mengaudit serta mengevaluasi elemen-elemen fisik pada jalur pedestrian berdasarkan hasil pengamatan peneliti dan persepsi responden/ masyarakat, untuk mengetahui persepsi individu atau masyarakat terhadap tempat atau lingkungannya (Darjosanjoto, 2011).

Dalam penelitian ini menggunakan metode pengumpulan data observasi, kuesioner, wawancara dan dokumentasi. Data kualitatif hasil jawaban responden mengenai kondisi jalur pedestrian dikuantitatifkan dan diukur dengan menggunakan skala Likert.

Subyek populasi adalah masyarakat pada kawasan penelitian meliputi para pedestrian atau pejalan kaki yang berada pada koridor Jalan P.B Sudirman. Teknik pengambilan sampel yang digunakan adalah non probability sampling dan cara pengambilan sampel menggunakan purposive sampling.

\section{PRINSIP LIVABLE CITY}

Menurut (Palej, 2000) sebuah kota yang livable harus memiliki kehidupan yang sehat dan memiliki mobilitas yang mudah terutama dengan berjalan kaki. Untuk menciptakan kota yang livable maka sebuah kota harus memenuhi prinsipprinsip dari livable city (Makalalag, 2019). Prinsip-prinsip berikut ini disarankan sebagai dasar livable city oleh (Lennard, 1997) yaitu :
1. Sebuah kota yang baik memiliki wilayah/area publik sebagai tempat sosialisasi yang sangat diperlukan untuk semua masyarakat.

2. Sebuah kota yang baik memiliki wilayah/area publik sebagai tempat sosialisasi yang sangat diperlukan untuk semua masyarakat.

3. Aktivitas, dialog dan komunikasi masyarakat sangat penting.

4. Kota harus memenuhi fungsi ekonomi, sosial dan budaya.

5. Pertimbangan terhadap estetika atau keindahan dan lingkungan fisik harus memiliki prioritas tinggi.

Livable city memiliki kriteria-kriteria yang terdiri dari berbagai ranah baik wilayah di tingkat lokal, nasional bahkan dunia. Kriteria dapat disesuaikan dengan ranah wilayah kota/ kawasan (Kristarani, 2017).

Kota Nganjuk agar berkembang serta memiliki aktivitas masyarakat yang meningkat haruslah menjadi kawasan yang livable. Upaya ini dilakukan melalui terpenuhinya prinsip-prinsip livable city dengan berawal dari koridor Jalan P.B Sudirman yang memiliki potensi dengan tersedianya tempat atau ruang publik bagi masyarakat yang memiliki nilai estetika yang tinggi dan terutama memiliki mobilitas yang mudah bagi pejalan kaki atau pengguna jalur pedestrian.

\section{JALUR PEDESTRIAN}

Jalur pedestrian adalah salah satu bagian dari ruang terbuka publik yang memegang peranan penting bagi sebuah kota sehingga memerlukan akses yang walkable (nyaman dan baik untuk digunakan berjalan kaki) tanpa ada gangguan atau halangan (Farida, 2017).

Jalur pedestrian merupakan sarana perkotaan khususnya koridor jalan untuk melindungi dan memfasilitasi pejalan kaki. Jalur pedestrian harus memfasilitasi semua elemen masyarakat diantaranya masyarakat lanjut usia, penyadang cacat, perempuan mengandung dan anak-anak (Setyowati, 2017).

Menurut (Shirvani, 1985) dalam perancangan sebuah kota, jalur pedestrian sebagai fasilitas pejalan kaki harus dipertimbangkan 
dengan baik karena merupakan bagian dari elemen urban desain.

Syarat jalur pedestrian menurut (Shirvani, 1985) adalah:

1. Aman, leluasa dalam bergerak dengan cukup terlindung dari lalu lintas kendaraan.

2. Nyaman, bebas dari hambatan dan gangguan yang disebabkan oleh ruang yang sempit seperti adanya pedagang kaki lima dan parkir kendaraan.

3. Diberikan elemen-elemen yang dapat menimbulkan daya tarik seperti lampu-lampu penerangan, pot bunga dan pohon peneduh.

4. Dapat memfasilitasi pejalan kaki yang menderita cacat fisik seperti tuna netra, terutama pada pusat-pusat aktivitas seperti perkantoran, pendidikan, dan perdagangan.

Keberadaan jalur pedestrian pada sebuah kawasan/ kota adalah hal yang sangat penting untuk memfasilitasi para pejalan kaki terutama dari penyalahgunaan jalur akibat berbagai kegiatan seperti parkir kendaraan dan perdagangan. Keselamatan dan kenyamanan pejalan kaki harus menjadi fokus utama dengan penggunaan material yang aman, tidak licin dan menyilaukan (Handayani, 2018).

\section{HASIL DAN PEMBAHASAN}

Dalam pembahasan akan dipaparkan mengenai jalur pedestrian yang memenuhi kriteria livable city dengan penerapan teknik analisa walk through - single directional views.

Koridor Jalan P.B Sudirman terbagi menjadi 2 (dua) karakter penggal jalan, yaitu : Penggal Jalan A dan Penggal Jalan B karena adanya perbedaan karakter kawasan yang dominan. Dalam pemanfaatan guna lahan yang ada untuk sisi penggal jalan A didominasi oleh perdagangan dan jasa. Sedangkan, penggal jalan B didominasi oleh hunian permukiman dan perdagangan/ jasa sektor kecil-menengah.

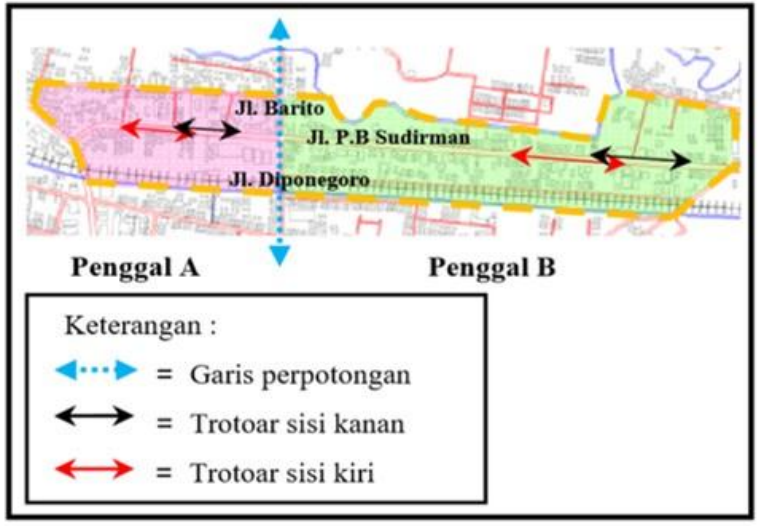

Gambar 1. Penggal A dan B koridor Jalan P.B Sudirman

\section{Analisis Jalur Pedestrian}

Jalur pedestrian koridor Jalan P.B Sudirman Nganjuk akan dibahas berdasarkan penilaian masyarakat dan penilaian peneliti.

1. Penilaian Masyarakat

Penilaian didasari oleh kapabilitas dan kelayakan jalur pedestrian untuk dapat dilalui atau dilewati berdasarkan hasil pengamatan dan persepsi responden (melalui kuesioner) dengan menggunakan empat kriteria yaitu: kejelasan (conspicuous), kenyamanan (comfortable), kesesuaian (convenient) dan keramahan (convivial).

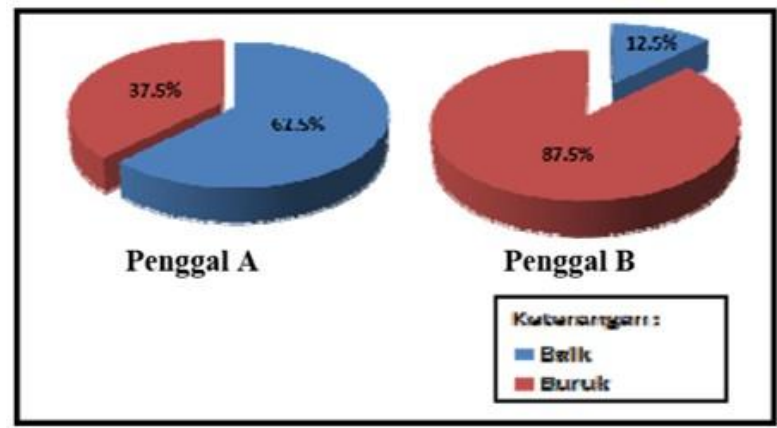

Diagram 1. Prosentase Penilaian Kondisi Jalur Pedestrian Penggal Jalan A dan B

Prosentase penilaian masyarakat terhadap kondisi jalur pedestrian pada penggal jalan A dengan penilaian baik sebesar $62,5 \%$ sedangkan penilaian buruk sebesar $37,5 \%$, hal ini membuktikan bahwa kondisi jalur pedestrian pada penggal jalan A memiliki kualitas yang cukup baik dengan perbandingan 2:1. Perbedaan ini mendasari perlunya upaya atau langkah pengembangan bagi jalur pedestrian pada penggal jalan A terlebih 
penggal ini merupakan kawasan perdagangan dan jasa yang sangat membutuhkan ketersediaan jalur pedestrian guna menunjang keberlangsungan aktivitas kawasan.

Prosentase penilaian masyarakat terhadap kondisi jalur pedestrian pada penggal jalan B mendapatkan penilaian buruk sebesar $87,5 \%$ sedangkan penilaian baik sebesar $12,5 \%$, hal ini membuktikan bahwa kondisi jalur pedestrian pada penggal jalan B memiliki kualitas yang sangat buruk dan perlu untuk dilakukan upaya perbaikan atau pengembangan. Perbedaan yang sangat besar ini mendasari perlunya upaya atau langkah pengembangan bagi jalur pedestrian penggal jalan B terlebih penggal ini merupakan kawasan dominan hunian yang sangat membutuhkan ketersediaan jalur pedestrian.

Kondisi jalur pedestrian yang baik merupakan syarat yang harus dimiliki oleh kawasan hunian bahkan setiap kawasan perkotaan memerlukan jalur pedestrian yang baik dan dapat memfasilitasi masyarakat (mobilitas pejalan kaki) guna terciptanya livable city. Melalui jalur pedestrian yang baik diharapkan masyarakat tertarik untuk berjalan kaki dibanding berkendara dengan kendaraan bermotor sehingga aktivitas masyarakat pada koridor Jalan P.B Sudirman dapat meningkat sekaligus dengan masyarakat memilih untuk berjalan kaki dibanding menggunakan kendaraan bermotor akan mengurangi polusi udara dan hal ini sangat baik terutama bagi kawasan hunian.

\section{Penilaian Peneliti}

Untuk mengetahui penilaian atau sudut pandang peneliti terhadap jalur pedestrian pada penggal jalan A dan penggal jalan B maka digunakan teknik analisa walk through. Teknik analisa ini berkaitan dengan teori image kota dari (Lynch, 1960) yang fokus pada path.

Path, Single Directional Views. Setiap foto menunjukkan streetscape yang kedudukannya dalam peta dipandu oleh panah. a. Penggal jalan A, diambil dari titik diarea perempatan Jl. P.B Sudirman-Jl. DiponegoroJl. Barito.

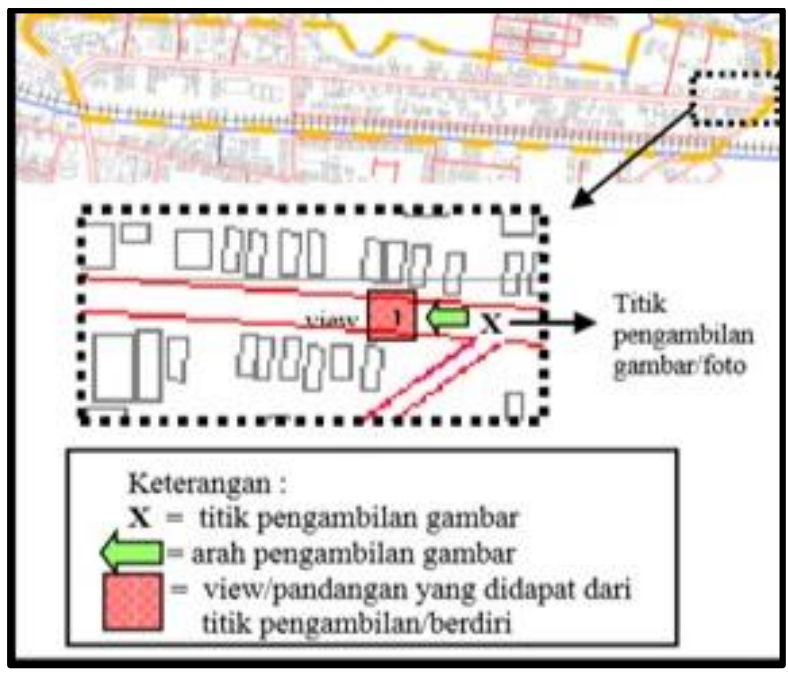

Gambar 2. Single Directional Views Pada Penggal Jalan A

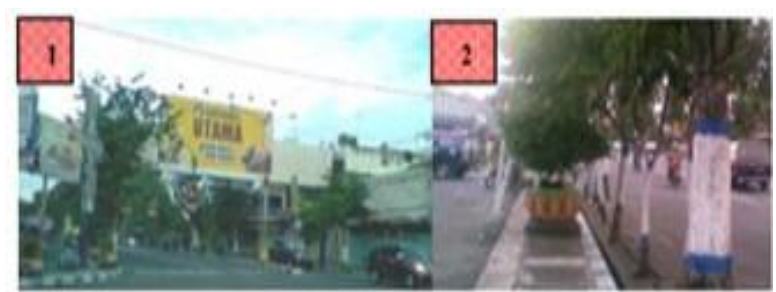

Gambar 3. View dari titik pengambilan pagi hari pukul 06.00-10.00 WIB

Kondisi trotoar pada pagi hari terlihat cukup teduh karena belum panas oleh terik matahari. Selain itu, jalur pedestrian terhalang oleh pot tanaman yang diletakkan pada badan trotoar yang mengganggu kenyamanan pejalan kaki.

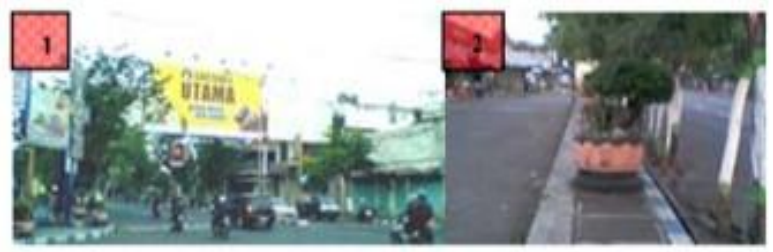

Gambar 4. View dari titik pengambilan siang hari pukul 10.00-16.00 WIB

Kondisi trotoar pada siang hari terasa panas/terik karena kurang memiliki vegetasi yang cukup, kurang terjaga kebersihannya dan tidak memiliki pelindung sisi trotoar. Dimensi trotoar belum memenuhi standar lebar minimal 1,5 meter. 


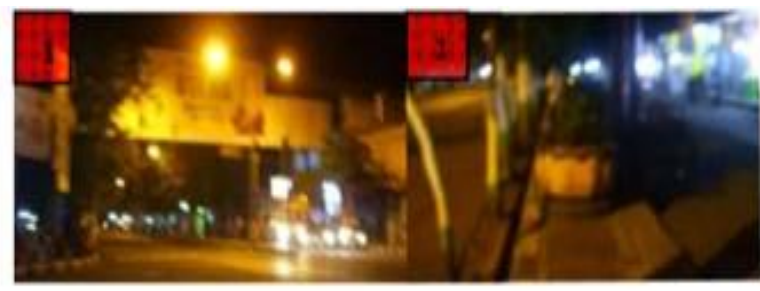

Gambar 5. View dari titik pengambilan siang hari pukul 10.00-16.00 WIB

Pada malam hari jalur pedestrian membutuhkan pencahayaan yang lebih terang. Terlihat pada gambar 6 kondisi trotoar memiliki pencahayan yang remang (tidak terang).

b. Penggal jalan $\mathrm{B}$, diambil dari titik area persimpangan jalan P.B Sudirman (tugu Adipura) dengan jalan Mastrip.



Gambar 6. Single Directional Views Pada Penggal Jalan B



Gambar 7. View dari titik pengambilan pagi hari pukul 06.00-10.00 WIB

Pada pagi hari masyarakat aktif memulai aktivitas seperti berolahraga dan menyapu. Namun sayangnya terjadi penyalahgunaan trotoar sebagai tempat duduk (terdapat kursi pada badan trotoar) dan terdapat kerusakan pada trotoar.

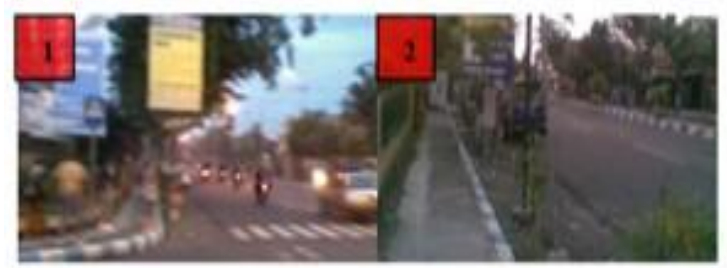

Gambar 8. View dari titik pengambilan siang hari pukul 10.00-16.00 WIB

Kondisi jalur pedestrian/trotoar pada siang hari sedikit dilalui oleh pejalan kaki atau pengguna jalan karena kondisi siang hari yang panas dan terik. Selain itu, dimensi lebar trotoar belum memenuhi standard lebar minimal 1,5 meter.

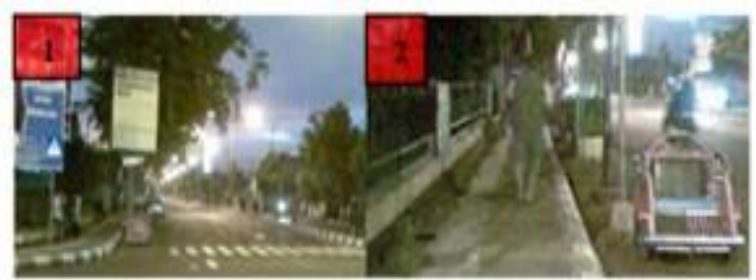

Gambar 9. View dari titik pengambilan malam hari pukul 16.00-22.00 WIB

Pada malam hari jalur pedestrian membutuhkan pencahayaan yang lebih terang dan membutuhkan pengaman tepi trotoar terutama pada malam hari. Selain itu, pada bahu jalan sering difungsikan untuk parkir kendaraan atau pangkalan becak.

Berkaitan dengan sifat Jalan P.B Sudirman sebagai city gate/gerbang masuk kota Nganjuk maka diperlukan upaya pengembangan yang dilakukan melalui jalur pedestrian/path. Jalur pedestrian diberi rancangan agar memiliki kekhasan/identitas yang membedakan dari kawasan sebelumnya, sehingga pengamat merasakan suasana yang berbeda saat memasuki koridor Jalan P.B Sudirman dan menjadi daya tarik bagi pengguna jalan/pejalan kaki untuk menggunakan jalur pedestrian.

Rangkuman Kondisi Jalur Pedestrian Penggal A dan Penggal B adalah :

1) Masalah :

a) Jalur pedestrian memiliki pencahayaan yang kurang pada malam hari. 
b) Ketidaksesuaian terhadap standard jalur pedestrian dengan lebar hanya 1 meter dan terhalang oleh pot tanaman, dengan demikian trotoar belum memiliki fungsi yang jelas sebagai jalur pejalan kaki.

c) Kondisi jalur pedestrian banyak mengalami kerusakan seperti berlubang dan terhalang oleh benda/ aktivitas lain.

d) Jalur pedestrian belum memberikan perlindungan bagi panas dan hujan karena jumlah vegetasi yang kurang dan tidak adanya tempat perhentian untuk berteduh.

e) Jalur pedestrian belum memiliki pengaman pada sisi jalur serta tidak memiliki daya tarik atau ciri khas ataupun street furniture.

2) Pemecahan dan potensi :

a) Perbaikan jalur pedestrian dengan lebar sesuai standard minimal 1,5 meter dan menghilangkan penghalang.

b) Pemberian pencahayaan yang maksimal pada malam hari.

c) Pemberian elemen pelindung.

d) Penambahan vegetasi dan elemen peneduh.

e) Path (jalur pedestrian) berpotensi untuk dikembangkan menjadi identitas atau memperkuat kekhasan kawasan melalui rancangan yang menarik.

Berdasarkan analisa dari kedua penggal

jalan diatas didapat bahwa masing-masing penggal jalan dengan karakter yang dimiliki perlu adanya suatu upaya pengembangan terhadap jalur pedestrian terutama menjadikan jalur pedestrian lebih menarik sekaligus dapat menjadi image/ identitas dari kawasan. Kriteria keramahan (convivial) dihadirkan disini melalui desain yang tepat untuk menciptakan suatu daya tarik yang khas bagi koridor, dengan adanya kehasan identitas/image akan membuat para pengamat dan pengguna jalan lebih semakin tertarik untuk berjalan kaki di koridor penelitian.

\section{Arahan Perancangan Jalur Pedestrian}

Perancangan disesuaikan dengan prinsip atau kriteria dari livable city. Dalam hal ini yang akan ditekankan pada konsep perancangan jalur pedestrian adalah nilai estetika, memenuhi fungsi sosial dan budaya serta kenyamanan dan kemudahan mobilitas bagi pejalan kaki dengan memfasilitasi pejalan kaki yang menderita cacat fisik dan berusia lanjut.

Prinsip/ kriteri sebagai dasar rancangan dari jalur pedestrian adalah :

- Jalur pedestrian memiliki corak/ motif yang berciri khas/ budaya

- Jalur pedestrian berdasar pada Pedoman Teknik Persyaratan Aksesibilitas Pada Jalan Umum No. 022/T/BM/1999 (Direktorat Jenderal Bina Marga, 1999)

- Penempatan street furniture yang tertata dan memiliki ciri khas/ nilai budaya

- Pemilihan jenis vegetasi yang berciri khas/ lokal Nganjuk, meneduhkan, menyerap polusi, mengurangi kebisingan dan menambah estetika kawasan.

Konsep rancangan meliputi konsep jalur pedestrian, street furniture, vegetasi dan pengaman.

1. Jalur pedestrian

a. Menggunakan penutup (hardscape) dengan motif batik Nganjuk yang dapat menjadi ciri kawasan.

b. Menggunakan bahan yang tidak licin dan datar agar memudahkan pengguna jalan/ pejalan kaki terutama yang menderita cacat fisik ataupun yang berusia lanjut untuk berjalan/ bergerak pada jalur pedestrian.

c. Jalur pedestrian dirancang memiliki lebar 1,8 $\mathrm{m}$ agar pengguna kursi roda dapat saling sejajar/ berdampingan melalui satu dengan yang lain, selain itu dimensi yang cukup lebar akan memberikan kenyamanan bagi para pengguna jalan (dinamik).

d. Jalur pedestrian dirancang memiliki jalur khusus bagi penyandang tuna netra agar dapat berjalan dengan aman yaitu menggunakan ubin pemandu (ubin garisgaris) dan ubin peringatan (ubin dot/ bulat). 
e. Jalur pedestrian diberi handrail dengan ketinggian 0,6-0,75 meter yang sesuai untuk pengguna ramp sebagai keamanan pengguna kursi roda sekaligus dapat berfungsi membantu para lansia untuk berdiri saat berhenti sejenak. Perancangan ramp agar dapat memfasilitasi pengguna kursi roda mengikuti standar dimensi pelandaian yaitu 2.5 meter dengan bahan bertekstur dan memiliki pengaman. Untuk menghindari selip, pembatas rendah pinggir ramp (curb ramp) dirancang untuk menghalangi kursi roda agar tidak terperosok keluar dari jalur. Selain itu, jalur pedestrian dilengkapi dengan elemen/ tiang peneduh pada beberapa spot sebagai tempat berteduh saat hujan.

2. Street furniture (lampu penerang dan bak sampah)

Lampu penerang dan bak sampah memiliki bentuk khas sebagai nilai budaya/ciri Nganjuk untuk mengangkat karakter/memperkuat kekhasan dari koridor Jalan P.B Sudirman sekaligus memberi nilai estetika dan membuat kondisi trotoar lebih menarik dengan mengadaptasi dari logo Kabupaten Nganjuk.

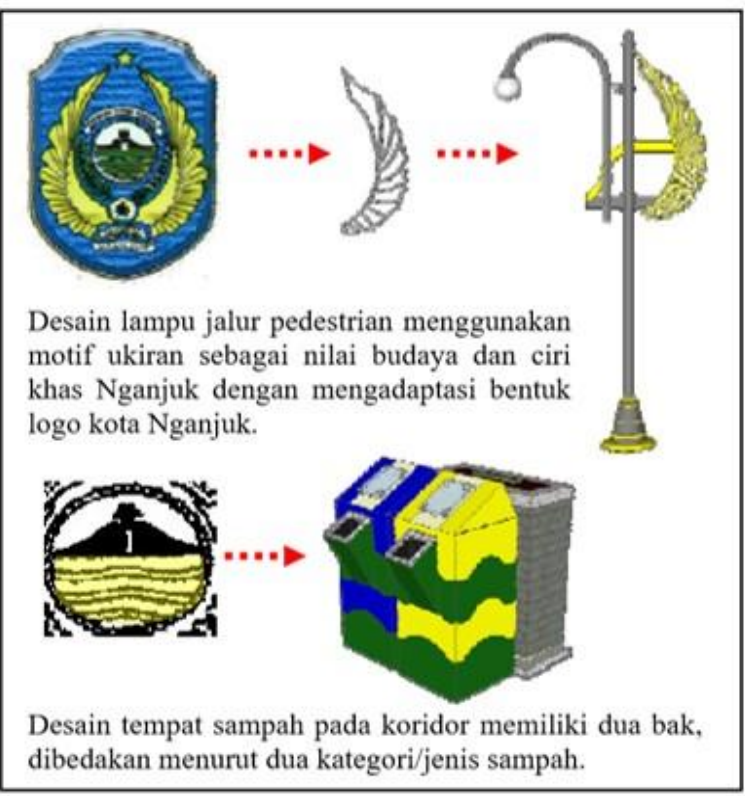

Gambar 10. Street Furniture Jalur Pedestrian
3. Vegetasi

Letaknya di luar ruang dan berada pada jalur jalan, jalur pedestrian memerlukan vegetasi yang berfungsi sebagai :

- Peneduh : kiara payung (Fellicium Decipiens)

- Penyerap polusi udara : bugenvil (Bougenvillea Spectabilis)

- Penyerap kebisingan kendaraan : kiara payung (Fellicium Decipiens), bugenvil (Bougenvillea Spectabilis) dan kembang sepatu (Hibiscus rosa sinensis)

- Penambah nilai estetika : palem putri (Veitchia merrilli)

4. Pengaman

Pengaman jalur pedestrian bagi keamanan pejalan kaki dari kendaraan adalah pada siang hari terlindung dengan vegetasi dan pot/ box tanaman serta kejelasan warna dari jalur pedestrian. Sedangkan, pada malam hari dibantu dengan paku jalan (mata kucing) yang dapat bercahaya pada malam hari

\section{Gambar Desain/ Rancangan}

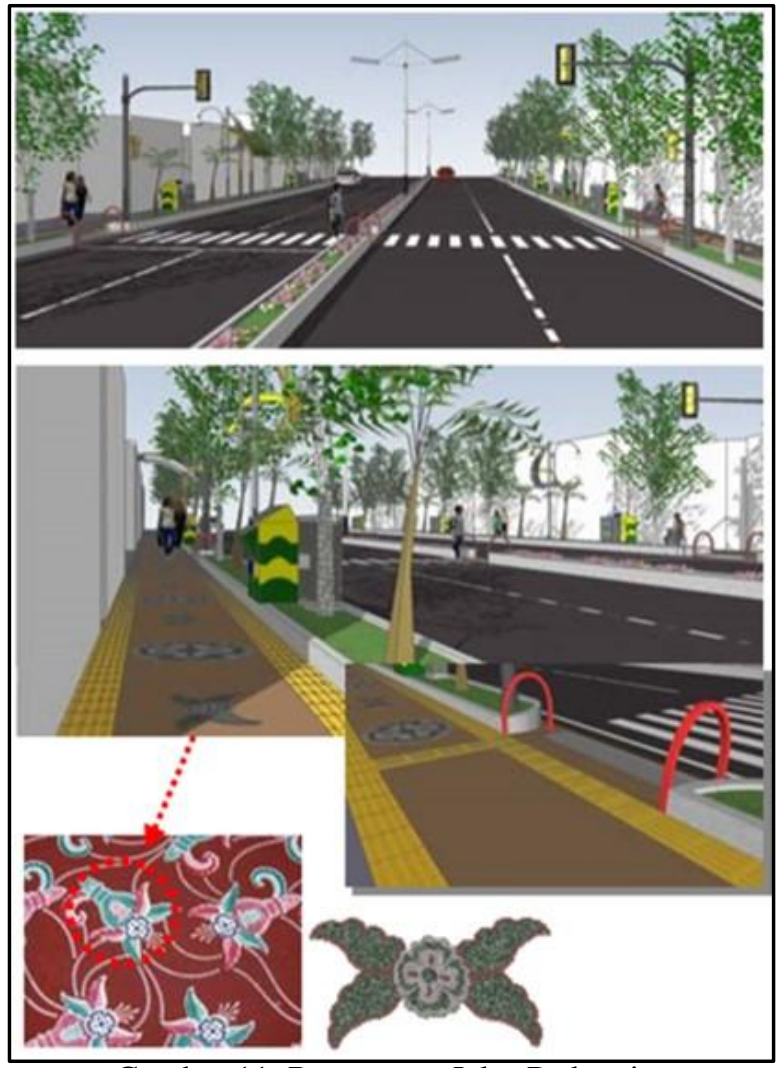

Gambar 11. Rancangan Jalur Pedestrian

Jalur pedestrian dirancang menggunakan motif batik Nganjuk (nilai budaya) dan memiliki ubin pengarah sebagai fasilitas bagi tuna netra. 
Jalur pedestrian juga dirancang memfasilitasi penderita cacat fisik/ pengguna kursi roda dengan dimensi 1,8 meter, permukaan datar dan tersedianya ramp yang aman (permukaan bergelombang dan terdapat pengaman pada bawah ramp) serta railing.

\section{PENUTUP}

\section{Simpulan}

Berdasarkan penelitian yang telah dilakukan maka dapat diambil beberapa kesimpulan yaitu sebagai berikut :

1. Perancangan jalur pedestrian harus memperhatikan kebutuhan pengguna jalan, yang meliputi:

a. Keselamatan atau keamanan (safety) seperti pengguna jalan anak-anak, lansia atau orang dengan keterbatasan fisik yang memerlukan fasilitas khusus. Selain itu pejalan kaki/ pengguna jalan dapat aman dari tindakan kriminal dan tindak kejahatan lainnya dengan adanya penerangan yang cukup terutama pada malam hari dan pandangan yang tidak terhalangi.

b. Kenyamanan (comfort) dengan tidak adanya rintangan atau halangan di sepanjang jalur pedestrian, seperti berlubang, permukaan yang tidak rata, anak tangga, dimensi menyempit, dan kemunculan aktivitas lain di jalur pedestrian.

c. Kenikmatan (pleasure) dapat dicapai dengan menyediakan pelindung bagi pengguna jalan semisal dengan adanya pepohonan, sehingga pengguna terlindung dari cuaca panas, hujan dan angin. Selain itu dapat juga dengan memberikan street furniture seperti lampu penerang dan tempat sampah.

2. Jalur pedestrian dirancang memiliki dimensi sebesar 1,8 meter agar dua kursi roda dapat beriring/ saling melewati, ramp yang disesuaikan bagi pengguna kursi roda, ubin pemandu dan ubin peringatan bagi tuna netra dengan ukuran $30 \times 30 \mathrm{~cm}$.

3. Estetika merupakan aspek penting bagi koridor yang livable sehingga kawasan memiliki daya tarik/ ciri khas. Nilai dihadirkan dengan penggunaan motif batik khas Nganjuk pada penutup/ paving jalur pedestrian, adaptasi logo Kabupaten Nganjuk pada street furniture (lampu dan bak sampah).

\section{Saran}

Peneliti menyadari masih banyak kekurangan dari penelitian ini yang terbatas hanya pada jalur pedestrian di koridor jalan P.B. Sudirman. Harapan peneliti agar penelitian selanjutnya dapat memperluas penelitian dan arahan desain pada elemen kota yang lain seperti pada ruang terbuka, fasad bangunan, landmark, taman/ lansekap, dsb.

\section{DAFTAR PUSTAKA}

Darjosanjoto. (2012). Walk Through Analysis. Surabaya: ITS.

Direktorat Jenderal Bina Marga. (1999). Pedoman Teknik Persyaratan Aksesibilitas Pada Jalan Umum No. 022/T/BM/1999. Jakarta.

Farida, I. (2017). Tingkat Kesesuaian Ruang Publik Dengan Konsep Livable City di Kota Surakarta. Jurnal Arsitektura, Vol. 15, No.1.

Handayani, S. (2018). Tinjauan Sarana dan Prasarana Jalur Pedestrian di Kawasan Peunayong, Banda Aceh. Jurnal Arsip Rekayasa Sipil dan Perencanaan, Vol. 1, No. 1. DOI: 10.24815/jarsp.v1i1.10357.

Kristarani, dkk. (2017). Perumusan Indikator Livable City Kota Sedang di Kota Magelang. Prosiding Seminar Nasional XII "Rekayasa Teknologi Industri dan Informasi 2017 Sekolah Tinggi Teknologi Nasional Yogyakarta, hal 391-398.

Lennard, S. H. (1997). Making Cities Livable. International Conferences. California: Gondolier Press.

Lynch, K. (1960). The Image Of The City. England: Massachusetts Institute of Technology.

Makalalag, dkk. (2019). Kajian Kota Kotamobagu Menuju Kota Layak Huni (Livable City). Jurnal Spasial Vol. 6, No. 2. ISSN 24423262. 
Palej, A. (2000). Architecture for, by and with Children: A Way to Teach Livable City. The International Making Cities Livable Conference. Vienna.

Shirvani, H. (1985). The Urban Design Process. New York: Ubin.

Setyowati. (2017). Pemanfaatan Pedestrian Ways di Koridor Komersial di Koridor Jalan Pemuda Kota Magelang. Jurnal RUAS, Vol. 15, No 1. ISSN 1693-3702. 